\title{
Las Misiones Jesuíticas entre los Guaraníes y los impactos en las fronteras de la América Latina ${ }^{1}$
}

\author{
As Missões Jesuíticas entre os Guarani e os impactos nas \\ fronteiras da América Latina
}

\author{
The Jesuitic Missions among the Guarani and the impacts \\ on the borders of Latin America
}

\author{
Antonio Hilario Aguilera Urquiza² \\ Priscila Lini
}

DOI: http://dx.doi.org/10.20435/tellus.v19i40.630

\begin{abstract}
Resumen: La investigación trata sobre las Misiones Jesuíticas de los Guaraníes y su relevancia en el diseño de las fronteras coloniales y negociaciones territoriales efectuadas por Portugal y España en su consolidación en la zona continental, tanto en el elemento humano cuanto geográfico. La ubicación estratégica convenientemente congregó el resguardo territorial, y, de manera distinta, utilizaba el propio elemento humano nativo como factor colonizador. La expresiva extensión que conformó las misiones - en todas sus fases y desplazamientos - abarcó desde la actual Bolivia, Paraguay, Brasil y Argentina, estableciendo nuevos hábitos productivos. El fin del período de las Misiones tuvo razón por diversos factores, no cabiendo apuntar sólo un acontecimiento responsable de este cierre. Lógicamente, la negociación de la tierra entre Portugal y España comenzó el proceso, pero esto debe añadirse la expulsión de los jesuitas y la incapacidad de la nueva administración establecida por la Corona. Los movimientos de independencia que movieron a América Latina en la transición de los siglos XVII y XIX vendrían a poner fin a lo que sobraba de la autoridad colonial allí vigente, incorporando los territorios en definitivo en las fronteras de los recién formados estados nacionales, proporcionando un vacío que permitió la expoliación territorial de forma intensa. Para este trabajo se realizaron investigaciones en fuentes primarias de centros de documentación, acervos y repositorios de la bibliografía disponible, de forma interdisciplinaria, buscando el análisis no sólo jurídico, sino también histórico, antropológico y
\end{abstract}

1 La base de este texto fue presentada inicialmente en el VIII SIMPÓSIO INTERNACIONAL DE GEOGRAFIA AGRÁRIA (SINGA), Curitiba, PR, 1 a 5/11/2017; sigue acá reformulada por los autores.

2 Universidade Federal de Mato Grosso do Sul (UFMS), Campo Grande, Mato Grosso do Sul, Brasil. 
geográfico de las Misiones Jesuíticas de los guaraníes y sus reflejos coloniales, sobre diversos prismas ideológicos.

Palabras clave: fronteras; Misiones; Guaraní.

Resumo: A pesquisa trata das Missões Jesuíticas dos Guarani e sua relevância no desenho das fronteiras coloniais e das negociações territoriais efetivadas por Portugal e Espanha em sua consolidação no domínio continental, tanto no elemento humano quanto geográfico. A localização estratégica convenientemente congregou o resguardo territorial e, de maneira distinta, utilizava o próprio elemento humano nativo como fator colonizador. A expressiva extensão que conformou as Missões - em todas as suas fases e deslocamentos - abrangeu, desde a atual Bolívia, Paraguai, Brasil e Argentina, estabelecendo novos hábitos produtivos. O fim do período das Missões teve razão por diversos fatores, não cabendo apontar somente um acontecimento responsável por este encerramento. Logicamente, a negociação das terras entre Portugal e Espanha deu início ao processo, mas a isto se deve somar a expulsão dos jesuítas e a inabilidade da nova administração estabelecida pela Coroa. Os movimentos de independência que movimentaram a América Latina na transição dos séculos XVII e XIX viriam pôr fim ao que sobrava da autoridade colonial ali vigente, incorporando os territórios em definitivo nas fronteiras dos recém-formados estados nacionais, proporcionando um vácuo que permitiu a espoliação territorial de forma intensa. Para este trabalho, foram realizadas pesquisas em fontes primárias de centros de documentação, acervos e repositórios da bibliografia disponível, de forma interdisciplinar, buscando-se a análise não somente jurídica, mas também histórica, antropológica e geográfica das Missões Jesuíticas dos guaranis e seus reflexos coloniais, sobre diversos prismas ideológicos.

Palavras-chave: fronteiras; Missões; Guarani.

Abstract: The research deals with the Jesuit Missions of the Guarani and their relevance in the design of the colonial frontiers and the territorial negotiations effected by Portugal and Spain in their consolidation in the continental domain, both in the human and geographical elements. The strategic location conveniently congregated the territorial shelter, and, in a distinctive way, used the native human element itself as a colonizing factor. The expressive extension that conformed the Missions - in all its phases and displacements, it included from the present Bolivia, Paraguay, Brazil and Argentina, establishing new productive habits. The end of the Missions period was justified by several factors, and it is not enough to point out just one event responsible for this closure. Of course, the negotiation of the lands between Portugal and Spain began the process, but to this must be added the expulsion of the Jesuits and the inability of the new administration established by the Crown. The independence movements that moved Latin America in the transition of the seventeenth and nineteenth centuries would put an end to what was left of the colonial authority there, incorporating the territories definitively in the borders of the newly formed national states, providing a vacuum that allowed the territorial 
spoliation of intense form. For this work, the research was conducted in primary sources of documentation centers, collections and repositories of the available bibliography, in an interdisciplinary way, seeking not only juridical, but also historical, anthropological and geographical analysis of the Jesuit missions of the Guarani and their colonial reflections, on various ideological prisms.

Keywords: frontiers; Missions; Guarani.

\section{INTRODUCCIÓN}

Las misiones jesuíticas conformaron una estrategia colonial de la Europa en la naciente Modernidad, con un carácter doble: mientras conquistaron el espacio, evangelizaban a los pueblos desconocidos de los continentes que se descortinaban, ampliando los dominios de una Iglesia Católica que perdía el espacio poco a poco para los movimientos reformistas. La dedicación y la competencia de los clérigos de la Compañía de Jesús fueron conocidas desde el extremo Oriente - a ejemplo de los Santos Mártires del Japón - a las selvas de la América recién descubierta.

En el corazón de esta salvaje América del Sur, la tarea misionera de los jesuitas junto a los grupos guaraníes resultó en una vertiente colonial única, que no raro gana contornos de utopía. Las "reducciones", espacios de reunión, catequización y organización cotidiana y productiva, florecieron en los territorios de las inmediaciones de la cuenca del Plata, desde el Guairá, el Tape y el Itatín. En estos espacios, los sacerdotes de la Compañía de Jesús modificaron sustancialmente el modo de vida y fijaron en núcleos poblacionales miles de guaraníes antes adeptos al sistema semántico de vida.

La elección de esta zona no se produce al azar, y su carácter estratégico revela los atritos permanentes entre Portugal y España, en algunos períodos suspensos por la Unión Ibérica, en otros períodos en espíritu beligerantes, y entre avances y retrocesos, el territorio misionero de la parte centro-sur del continente permaneció durante varios años en una característica única de ocupación - un espacio colonial, preponderantemente ocupado y defendido por los propios grupos humanos locales.

De esta interacción, se puede analizar que los efectos de la ocupación llevada a cabo por las misiones trajeron consecuencias fundamentales a la configuración del territorio en América del Sur, que permaneció en una situación de continuos 
conflictos y despierta diferentes intereses sociales, políticos y económicos hasta la actualidad. En este sentido, además de afectar profundamente las relaciones con los pueblos tradicionales, alteró la relación de la colonización en estos mismos territorios.

\section{LOS JESUITAS Y LA TAREA MISIONARIA PLATINA}

La orden jesuita, fundada por Ignacio de Loyola en Montmartre, Francia, comporta una nueva forma de organización religiosa, más adaptada a las demandas de la Modernidad de una Europa en expansión, con efervescencia de ideas renacentistas y con la Iglesia Católica bajo las graves amenazas reformistas y moriscas.

Los jesuitas tramaron con su gran disciplina, estudio y preparación, nuevos contornos a las órdenes religiosas tradicionalmente medievales, sustituyendo la fe abnegada y contemplativa a una fe más combativa y actuante.

Desde que surgieron, en 1534, los jesuitas eran diferentes. Nunca antes un orden concilió tan bien la sólida formación religiosa e intelectual de sus miembros con la disposición para participar en misiones que exigían resistencia física, capacidad de articulación política y buenas nociones de administración y finanzas. Por eso mismo, rápidamente, los jesuitas se firmam como el primer orden moderno del cristianismo, muy lejos de los patrones medievales de comportamiento. Sus miembros se convirtieron en confesores de reyes y líderes de expediciones a cualquier lugar donde un barco europeo pudiera llegar. Así, garantizaron que la fe cristiana dejara el territorio del antiguo Imperio Romano y alcanzase al resto del mundo, por primera vez desde el comienzo de la Edad Media. (CORDEIRO, 2016, p. 12).

Distribuidos en los nuevos continentes en descubrimiento, los jesuitas establecieron una estrategia muy propia, la tarea misionera, que establecía un contacto profundo y continuo con las comunidades encontradas. En Oriente, encontraron sociedades estables, organizadas, con ritos religiosos milenarios y autoridades plenamente establecidas. Ocurrió que en el continente al oeste, los pueblos encontrados no poseían el mismo refinamiento de costumbres, estaban en un estado de barbarie, por así decir. Carentes del Dios verdadero y de la vida regida, pero con todo el potencial para bien recibirlos, para tanto sólo sería necesario un esfuerzo de catequización y organización, al que denominaron "reducción".

La reducción es un método misional, que reúne a los indígenas en pueblos para que vivan "una vida más política y humana", según la concepción re- 
ligiosa e ideológica de la época. Varios son los elementos básicos sobre los que estructura el método. [...] La base económica es objeto de cuidados especiales. Los jesuitas, con un fuerte sentido de captación del modo de producción y de las formas de trabajo, propias de los guaraníes, mantuvieron los cultivos tradicionales y también el equilibrio entre las chacras de las familias particulares y los trabajos comunales. (MELIÀ, 1988, p. 82).

Especialmente en la región de la cuenca del Plata, las reducciones tuvieron lugar por una serie de factores. En primer lugar, el territorio debe ser asegurado en la cara de los avances portugueses. Por otra parte, los habitantes locales, además de la necesidad urgente de evangelización, necesitaban protección frente a los colonos españoles - ávidos de incorporarlos en los sistemas económicos de la encomienda o de la mita - y de los bandeirantes paulistas que adentraban los bosques a fin de predicar los indios que iban a alimentar los mercados de esclavos de las regiones cercanas a la costa atlántica.

La demanda por misioneros partió del propio gobierno provincial, que vio en la actividad jesuita una valiosa forma de ayuda a la colonización en un territorio tan extenso y, en cierta medida aislado. La reducción y catequización de los indios atendía tanto a la Corona, que ganaba más súbditos, a la Iglesia Católica, que conquistaba más fieles, y así, garantizaba que el territorio platino fuese efectivamente ocupado y defendido.

\section{EL TERRITORIO MISIONERO GUARANÍ}

Para el territorio hispano más allá de la línea de Tordesillas, las ciudades fundadas en el siglo XVI - Villa Rica del Espíritu Santo, Ciudad Real del Guairá, Santa Cruz de la Sierra, Buenos Aires - tenían como objetivo asegurar a España la cuenca del Plata y abrir la puerta navegación directa con la metrópolis. Sin embargo, la ruta atlántica no fue oficializada y la región del Plata quedó aislada y creció muy lentamente (BELASTEGUI, 2009, p. 16).

Las Misiones Jesuíticas con el pueblo guaraní comenzaron en la región que se denominó Guairá, entre los ríos Ivaí, Tibagi y Piquiri, actual estado de Paraná, Brasil. Fundadas a principios del siglo XVII, por petición del gobernador Hernando Arias de Saavedra, conocido al tiempo como Hernandarias, desde España se creó la Provincia Jesuítica del Paraguay, llegando las primeras misiones a las regiones del Guairá, del Tape y del Itatín. 
Además, los jesuitas tenían un colegio en Asunción que, en los primeros tiempos, les sirvió de base doctrinal y económica para las Misiones que desarrollaban. Esta demanda tuvo lugar pues la región del Guairá se mostraba un peligro a los dominios hispanos en la dirección de las ricas minas de plata de Potosí y ya parecía una ruta interesante a los bandeirantes paulistas.

Una de las mayores dificultades de la experiencia de las misiones era al mismo tiempo uno de sus grandes triunfos: la mayor parte de las ciudadelas jesuíticas estaban instaladas en una región estratégica, bien servida de ríos y cerca de centros urbanos expresivos y el estuario del río de la Plata. Esta fue una de las regiones más disputadas de América del Sur desde el inicio de la colonización. En 1531, Martim Afonso de Souza, el primer regente de Brasil, condujo personalmente expediciones al área, donde llegó a escapar con vida de un naufragio. Los moradores de San Vicente buscarían por muchas décadas las minas míticas (se sabe hoy inexistentes) que se igualar a las encontradas en otras regiones del continente, en especial en Perú y Bolivia. Geografía de las veces el río se considera la puerta de entrada al Imperio Inca y se disputaría por los colonizadores españoles y bandeirantes portugueses. (CORDEIRO, 2016, p. 144-5).

Gracias al trabajo de sacerdotes como José Cataldino y Simón Masceta las primeras misiones se erigieron a partir de 1609, multiplicándose rápidamente, lo que contó con el apoyo masivo del gobierno de las Provincias de Paraguay y del Río de la Plata, que determinaba incluso que les se facilitasen los medios de subsistencia, les fuese provista ayuda, pues de la parte de los padres habría ayuda recíproca (LINI, 2015, p. 49). "Todavía, quedaba determinado que 'ningún soldado o vecino vendría a inquietarlos con los achaques de que van por la mita'” (PASTELLS, 1912, p. 153).

En el año del 1610, los relatos contabilizaron aproximadamente veinte mil indios en las inmediaciones (PASTELLS, 1912, p. 176), que entre los intentos y errores congregaban los grupos indígenas, y, en el año 1610, relatos contabilizan aproximadamente veinte mil indios en las inmediaciones. Esta reunión de guaraníes reducidos, que iban condicionándose al trabajo y a la fe cristiana, no tardó en llamar la atención de los bandeirantes paulistas, que iniciaron sus incursiones en busca de indios para esclavizar, atacando las misiones y llevando prisioneros cientos de hombres, mujeres y niños.

En 1628, los primeros asaltos a las reducciones comenzaron, y los sacerdotes inmediatamente clamaron por socorro en Lima, para que la Real Audiencia de Charcas, con jurisdicción en las provincias de Paraguay y Río de la Plata, 
intercediera junto al rey y les garantizara ayuda militar. Entre los años de 1629 a 1631, se estima que las banderas paulistas han segado cerca de cuarenta mil almas. (CARBONELL, 1992, p. 82).

A fin de escapar de estos ataques, los sacerdotes organizaron una migración masiva hacia el sur, a las proximidades del Río Uruguay, en la actual frontera entre Brasil y Argentina.

Ante la magnitud de tantos ataques, a fines de 1631, el Padre Montoya organizó la retirada de aproximadamente doce mil indios, entre remanentes de las misiones atacadas y refugiados de Loreto y San Ignacio. La jornada, que fue llamada "Gran Éxodo Guaraní" comenzó por barco, yendo a aguas del río Paraná y Yabeberí. La destrucción de las canoas, el agotamiento de las provisiones, los riesgos de las selvas y las enfermedades hicieron que este trayecto extremadamente dificultoso, sobreviviendo al fin, cerca de cuatro mil indios. (CARBONELL, 1992, p. 83-4).

El desplazamiento a las regiones del Tape no significó la paz definitiva, pues los ATAQUES continuaron. Sólo cuando la Corona española autorizó que los guaraníes empuñaran armas y defendiesen las reducciones es que las banderas cesaron, dando inicio al período misionero más estable, que duró más de cien años y resultó en cerca de treinta agrupamientos en las dos orillas del río Uruguay.

Es necesario entender la situación de la frontera de treinta personas de las Misiones Guaraníes frente al expansionismo del imperio portugués. Esta situación estratégica, en un área en la que los españoles estaban progresivamente perdiendo territorios, llevó a la monarquía hispánica a hacer concesiones, armando a los indígenas con armas de fuego, considerándolos como una milicia de apoyo. (KERN, 1994. p. 75).

Esta defensa territorial, así como el progreso económico que las reducciones fueron obteniendo, con la actividad agrícola, pecuaria, hierbatera y manufacturera, en muy agradó a España en los primeros años. La hierba mate de excelente calidad, la carne y el cuero producidos en las vaquerías y estancias, los artefactos de madera - instrumentos musicales, arte sacro y utensilios - eran adquiridos no sólo en Buenos Aires y Asunción, sino también en Europa.

Así, las Misiones platinas experimentaron un período de gran desarrollo y prestigio, congregando en el territorio amplio a que se denominaba Paraguay (que corresponde actualmente a las fronteras entre Argentina, Brasil y Paraguay) un sistema colonial impar. 
Figura 1 - Paraqvaria vulgo Paragvay - grabado de Arnoldus Montanus, 1671

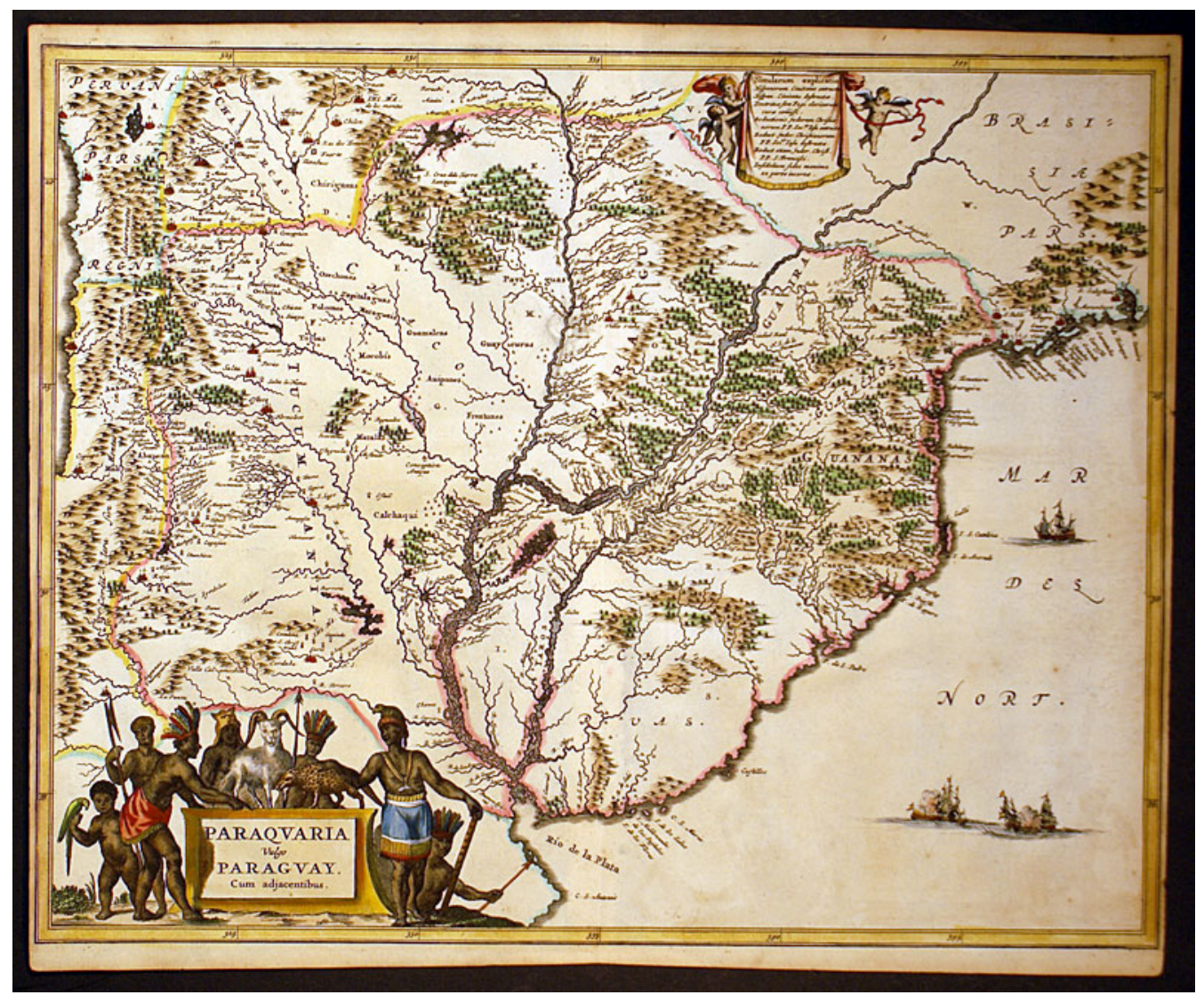

Fonte: Archivo Histórico del Itamaraty, Mapoteca, Rio de Janeiro.

Este éxito, en la segunda mitad del siglo XVIII, pasa a convertirse en una molestia, sea porque las relaciones entre España y Portugal se enfriaron, sea por la sospecha de que la Compañía de Jesús iba a enfrentar en la Europa de la Ilustración, y por lo tanto en las colonias.

Se produjo que, pasados más de cien años de las hostilidades emprendidas en el Guairá, la aproximación de los imperios y las reacomodaciones realizadas en la era de los Borbones alteraron completamente el ánimo del Estado español frente a la Provincia del Paraguay. La Colonia del Sacramento, tan cerca de la próspera y creciente Buenos Aires, en el estratégico estuario del Plata, ha convertido a esos treinta pueblos una excelente negociación para los nuevos contornos coloniales de América del Sur. (LINI, 2015, p. 118). 
Por lo tanto, la porción oriental del río Uruguay fue perdiendo importancia para España, debido a que la Colonia del Sacramento, en manos portuguesas despertaba mucho más preocupación de que cualquier intento de acceso a las áreas hacia el altiplano o la selva. Buenos Aires pasó a ser la prioridad, pues ya se mostraba un puerto fundamental a la economía metropolitana y garantizaba a España sus lucrativos dominios al Sur.

Aprovechando un período de reaproximación entre las dinastías ibéricas, la negociación del territorio del Plata fue puesta en marcha. El espacio misionero en su parte oriental tuvo de ser cedido a Portugal, que estaba desarrollando la economía tropera de Sorocaba, mirando al Sur por el ganado que se propagaba en las llanuras de bosques de pinos, y ocupando gradualmente el interior con los migrantes de los pueblos y parajes de troperos.

Por otro lado, Portugal entregó la Colonia del Sacramento, a las orillas del Río de la Plata, que ya no representaba un almacén tan interesante, sino más bien un punto de apoyo para el comercio de contrabando, lo que molestó a algunos políticos portugueses que tenían intereses directos en este mercado. Uno de los políticos que en principio se opuso a esta negociación fue el propio Marqués de Pombal, nombrado secretario de Estado por el Rey algunos meses después de la firma del Tratado de Madrid, pero posteriormente cambió de idea, pues en este aspecto predominó su antipatía a la causa jesuítica.

Así, el Brasil colonial, enriquecido por el oro de sus minas, se mantuvo alejado de las disputas que tal vez podrían estremecer las relaciones entre Portugal y España, por lo que tanto los gobernantes vendrían a alguna ventaja, redibujando sus dominios e intercambiando sus temas, aunque nunca hayan consultado a los habitantes de estos territorios.

\section{EL TRATADO DE MADRID Y LA NEGOCIACIÓN TERRITORIAL IBÉRICA}

El Tratado de Madrid, de 1750, reguló la situación incierta que las fragilidades del Tratado de Tordesillas habían dejado en el continente, redefinido el espacio entre los dos Estados, ahora, según los criterios fácticos. Era imposible ignorar los avances portugueses mucho más allá de la costa atlántica otorgado originalmente, así como España había superado los límites en la gran parte insular del este. Sin embargo, en aquel momento la prioridad era delimitar las 
fronteras en América del Sur, lo que se hizo con un Tratado tan amplio y osado como el primero.

Concluido el 13 de enero de 1750, el Tratado consagró el principio del uti possidetis, fundamental para la doctrina de límites que sería seguida por Brasil. Donde hubiera una verdadera ocupación, quedaba confirmada la posesión de los territorios en cuestión. Con eso, era formalmente revocado el Tratado de Tordesillas, cuyo meridiano nunca fue un límite efectivo. En realidad, la línea imaginaria que debería separar los dominios ibéricos en el Nuevo Mundo ya no existía en la práctica. El Tratado reconoció la situación de hecho, legitimándola por medio de un acto jurídico contraído con el libre consentimiento de las partes. (AMORIM in CORTESÃO, 2006a, p. 5).

En este contexto, las Misiones Jesuíticas fueron sólo en el centro de la cuestión, entonces, de largo, fueron utilizadas por España como una manera de contener los avances portugueses. Los Treinta Pueblos de las Misiones ocuparon una enorme extensión territorial, a la que se denominaba genéricamente de Paraguay, y, además de ser permanentemente pobladas, urbanizadas y lucrativas, todavía congregaban una población masivamente nativa, que mantenía su idioma y una forma peculiar de organización política y económica.

Se determinó entonces que España cedería los territorios del Río Grande de San Pedro, que congregaba siete de las treinta Misiones Jesuíticas de las adyacencias del río Uruguay, autorizando que los indios se trasladaran con sus pertenencias para las demás reducciones del lado español.

De las Poblaciones o Aldeas, que cede Su Majestad Católica en la orilla oriental del Río Uruguay, saldrán los Misioneros con todos los muebles, y efectos; llevando consigo los indios a los aldeanos en otras tierras de España; y los referidos indios podrán llevar también todos sus bienes muebles y semovientes, y las armas, pólvora y municiones, que tengan; en cuya forma se entregará a los Establecimientos de la corona de Portugal, con todas sus casas, iglesias y edificios, y la propiedad, y la posesión de la tierra. Las que se ceden por Sus Majestades Fidelísima y Católica en las márgenes de los ríos Pequiri, Guaporé, y de las Amazonas, se entregarán con las mismas circunstancias que la Colonia del Sacramento, según se ha dicho en el Artículo XIV: y los Indios de una y otra parte la misma libertad para que se vayan o queden de la misma manera, y con las mismas cualidades, que lo han de poder hacer los moradores de aquella plaza; excepto que los que se pierden la propiedad de los bienes de raíz, si los tienen. (CORTESÃO, 2006b. p. 370-1). 
Por su turno, Portugal tuvo de entregar la Colonia de Sacramento, situada en las orillas del Río de la Plata, y los residentes decidieron si deseaban permanecer allí, o se trasladar a las posesiones portuguesas, pudiendo así vender sus propiedades y llevar los bienes móviles y la ganadería.

La Colonia del Sacramento se entregará por Portugal, y no tomará más de artillería, armas, pólvora y municiones, y los mismos buques de servicio en plaza; y los residentes pueden permanecer libremente en ella, o retirarse a otras tierras de dominio portugués, con sus efectos y mobiliario y venta de bienes de raíz. El Gobernador, Oficiales y Soldados llevarán también todos sus efectos, y tendrán la misma libertad de vender sus bienes de raíz. (CORTESÃO, 2006b, p. 370).

Era de considerar que en este escenario de aproximación entre las coronas ibéricas, la presencia de la Compañía de Jesús con poderes políticos y económicos tan amplios, apoyados masivamente por los numerosos guaraníes reducidos, era cada vez más indeseada por ambas metrópolis. De esta forma, podrían resolver tanto la cuestión política entre sí, como respecto a aquella Orden religiosa que ya despertaba tanta desconfianza y animosidad en Europa.

Como se mencionó, la entrega de la Colonia del Sacramento no fue objeto de consenso, tampoco los siete pueblos de la orilla oriental de Uruguay se entregaron fácilmente, dando inicio a la llamada Guerra Guaranítica, que se extendió de 1750 a 1756, y dio origen a figuras míticas como Sepé Tiarayu y Nicolás Ñenguiru. Con la Batalla del Caiboaté, en 1756, las misiones de San Borja, San Miguel, San Lorenzo, San Nicolás, San Juan Bautista, San Luis Gonzaga y Santo Ángelo fueron tomadas, resultando este esfuerzo de resistencia de los misioneros en una verdadera masacre, padeciendo cientos de guaraníes.

Sucedió que los términos de dichos acuerdos eran extremadamente injustos, teniendo en cuenta que las tierras de los Siete Pueblos de las Misiones debían ser simplemente desocupadas sin ningún tipo de compensación o indemnización como estaba contenido en el Tratado: "a entregar los asentamientos a la corona de Portugal con toda sus casas, iglesias y edificios, y la propiedad, y posesión del terreno" (sic) - lo que no ocurrió con los habitantes de la Colonia del Sacramento. Además, cualquier compensación sería insuficiente al guaraní, pues su conexión con el territorio no era solamente física, sino espiritual. El amplio espacio ocupado siempre fue un elemento fundamental a la interacción del guaraní con la tierra. 
Como la cuestión no quedó pacificada por el primer Tratado, que resultó en incumplimientos contumaces de ambos lados, once años después se firmó el Tratado de El Pardo (1761), que hizo nulas todas las disposiciones anteriormente establecidas.

Aunque el Tratado de El Pardo tuvo, en teoría, retornado al estado de cosas anterior, la fricción con los jesuitas ya había afectado el estado de ánimo en las Misiones, cuya lealtad pasó a ser cuestionada por los indígenas. Se añade a esta situación regional el hecho de que tanto en España como en toda Europa, un clima adverso a la Compañía de Jesús se instalaba. En Portugal, la situación era aún más grave, cuando en 1759 se atribuyó a los jesuitas una conspiración para asesinar al Rey, lo que dio lugar a la expulsión de la Orden de todo el territorio portugués, incluyendo la secularización de sus misiones de Marañón y Gran Pará. En ese mismo clima de desconfianza, España adoptó igual política en sus dominios en Europa y en las Indias, y en el año 1767 el Rey Carlos III oficializó la expulsión de los jesuitas. (LINI, 2015, p. 125).

Pero después de tantos conflictos, volver al estado anterior era imposible, y la cuestión fáctica permanecía: los dominios hace mucho no coincidían con la línea imaginaria de Tordesillas. Era necesario dar una solución definitiva al caso, o que sólo se produjo en 1777 con el Tratado de San Ildefonso, firmado por el rey Carlos III de España y María I de Portugal. En ello, el Tratado de Madrid regresó a los términos originales y pacificó una vez que el dominio portugués sobre el territorio de los Siete Pueblos de las Misiones. Por lo tanto, las Misiones Jesuíticas, ya frágiles, sin duda pierden su espacio en el territorio portugués.

Con la expulsión de los jesuitas también en los territorios hispanos, los remanentes de las Misiones fueron entregados a otras órdenes religiosas y a las autoridades coloniales provinciales, que se mostraron totalmente inhabilidades para mantener el eficiente sistema económico y político hasta entonces mantenido por la Compañía de Jesús.

Muchos guaraníes pasaron a vivir en los campos, improvisando cabañas. Así, eran más libres y menos explotados que en las reducciones, donde tenían que pagar el alquiler de sus antiguas casas. Estas, empezaron a caer, así como las magníficas iglesias, las escuelas y los talleres. Veinticinco años después de la expulsión de los sacerdotes, Azara encontró esas construcciones abandonadas y parcialmente demolidas. (LUGON, 2010, p. 215). 
De esta forma, se diluyeron poco a poco los remanecientes de las misiones, restando a los guaraníes el retorno al modo de vida originario o la adaptación aunque precaria - al sistema colonial en curso, que luego sería sustituido por los nacientes Estados nacionales post independencias. El hecho es que en aquel gran espacio que abrigó las estructuras urbanas y rurales de las Misiones Jesuíticas, se sucedió un vacío que proporcionó a los Estados, en períodos posteriores, la posibilidad de distribución conforme a otros patrones colonizadores, que siempre priorizaron el europeo y el modelo productivo de explotación exhaustiva de la naturaleza y de la mano de obra.

\section{DE LA REPÚBLICA GUARANÍ A LOS ESTADOS LATINOAMERICANOS ACTUALES}

La tarea misionera asumida por los jesuitas, y el propio carácter de la Orden, sería determinante a la construcción del territorio y de la colonización americana que, dentro de los principios de una rígida moral cristiana, establecieron un escenario aparte, completamente distinto de los demás espacios de conquista (LINI, 2015, p. 29).

Comparando el mapa de 1671 con el mapa a seguir (Figura 2), es posible verificar que la presencia guaraní coincide con los territorios de las Misiones Jesuíticas, así como representa los espacios de ocupación más tardía en Brasil. Como comparación, se puede verificar que la fundación de las ciudades costeras como Curitiba, São Paulo, Florianópolis, Porto Alegre y Laguna datan de los siglos XVI y XVII, mientras que la ocupación efectiva del interior data de principios del siglo $X X$. 
Figura 2 - Mapa Guaraní Continental: Pueblos Guaraníes en la Argentina, Bolivia, Brasil y Paraguay

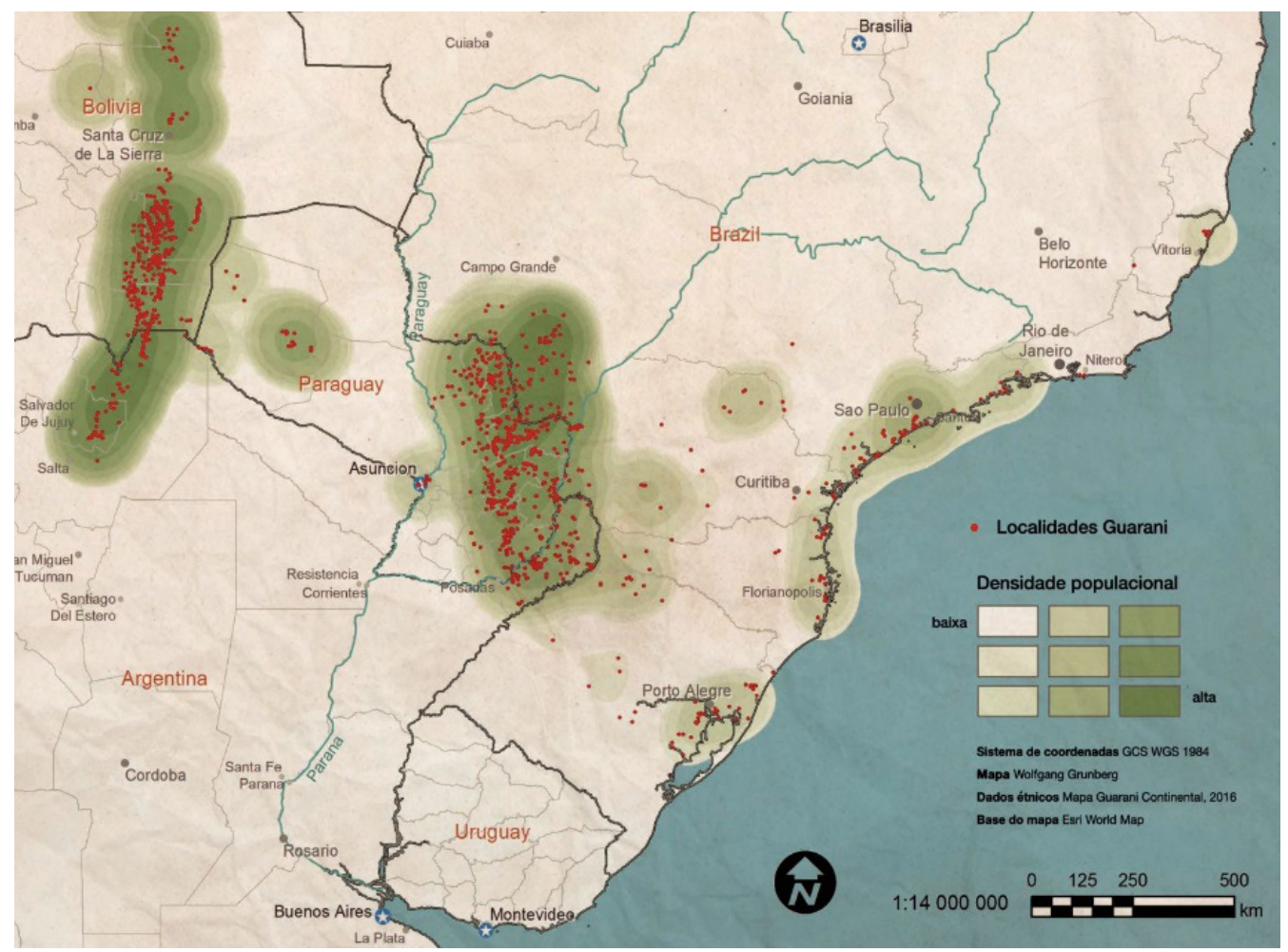

Fonte: Equipo Mapa Guaraní Continental (2016).

Este vacío se explica en gran parte por el vacuo territorial, político y jurídico dejado por el final del período misionero, así como por la ausencia de cualquier titulación o legitimación otorgada a los guaraníes en su espacio tradicional. Es interesante observar que en los siglos XVI y XVII todas las prerrogativas de dominio siempre fueron concedidas a la Compañía de Jesús, que recibían las autorizaciones para fundar las reducciones, sin que los guaraníes fueran directamente titulados.

Permanecían así en una situación de permanente "tutela", en un espacio concedido al orden religioso que allí dirigía económica y políticamente, con las estructuras del cacicazgo internamente establecidas. Pero en el momento de las tierras de los Siete Pueblos fueron entregados a Portugal, y la expulsión secuencial de los jesuitas, el privilegio de dominio no se concedió a los guaraníes, y regresaron 
en lugar considerado res nullius, o algo vago, sin dueño, por lo que es susceptible de apropiación por parte de los colonizadores.

En el lado español, con la expulsión de los jesuitas, las Misiones fueron entregadas a la administración de otras órdenes - que, en general, fracasaron -y poco a poco los indígenas o buscaron regresar a la condición anterior de vida tribal, o incluso se incorporan precariamente a la economía, condición de peatones de estancia o trabajadores serviles.

Este vacío territorial también se explicó por la dificultad en establecer villas y ciudades permanentes. Si la porción del pampa gaucho y de los campos generales, que en sus llanuras frías albergaron las primeras estancias particulares de ganado, concedidas por las comendas reales, los bosques a orillas del río Paraná presentaban una serie de dificultades para fijar pueblos y villas, pues el acceso por la mata era penoso.

Se añade a esta dificultad la reconfiguración de los estados nacionales tras las independencias y las disputas territoriales materializadas por la Guerra del Paraguay, y los remanentes de los territorios de las Misiones quedaron fragmentados y aislados.

Las primeras formas particulares de explotación económica en la región fueron las obras de extracción de yerba mate y madera, emprendidas por compañías argentinas y brasileñas a mediados del siglo XIX, que emplearon la mano de obra guaraní de manera exploratoria y cruel.

A cien kilómetros de las barrancas del Paraná ese frente pionero ya encontraba indígenas que, por hablar el guaraní, como aún se habla en el país vecino, eran llamados "paraguayos". Por eso, se identificaron agentes públicos (militares, gobierno federal y estatal) y privados (obrajeros y colonos) que consideraban que aquellos estaban en el lugar equivocado, porque allí ahora sería Brasil. Como principales afectados por la guerra de Paraguay, porque los conflictos se dieron sobre sus territorios, marginales a las hegemonías en formación y expansión, los indígenas pagaban su deuda como vencidos, siendo espoliados de su fuerza de trabajo. El indígena era un mensú, un peón que recibía por mes la más baja cantidad entre los trabajadores (SALLES; BERGOLD; VANESKI FILHO, 2016, p. 129).

Incomodadas con la presencia argentina, avanzando cada vez más por las márgenes del río Paraná, las autoridades brasileñas buscaban una forma de 
efectivamente establecer sus fronteras al oeste. Así, fundaron la Colonia Militar Iguassu en 1889, que tenía, entre otras prerrogativas la competencia para distribuir terrenos a colonos interesados, vinculada a la comarca de Guarapuava.

Sin embargo, es cierto que hasta la primera mitad del siglo XX las compañías de yerba mate y madereras tendrían primacía en los territorios interiores, así como los grandes estancieros más al sur. A continuación otros emprendimientos privados recibirían del Estado grandes concesiones de tierra para sus emprendimientos colonizadores.

A partir de la década de 1940, con la "marcha hacia el Oeste", las Ilamadas compañías colonizadoras asumirían la tarea de acomodar los intereses en relación a la propiedad de la tierra, recibiendo del propio Estado la prerrogativa de fraccionar y comercializar los espacios urbanos y rurales, formando ciudades planificadas dirigidas a la producción agrícola. Para ello, atrajeron los llamados 'colonos', oriundos de los estados Rio Grande do Sul y Santa Catarina, descendientes de los inmigrantes europeos que se instalaron en Brasil a mediados de los siglos XIX y XX.

De esta transformación del espacio, resultaron una serie de problemas sociales, especialmente en relación a los pueblos tradicionales, que siempre permanecieron marginados, o incluso ocultados. El guaraní, en este contexto, fue usurpado de su territorio y su cosmología por más de cuatro siglos, en las diversas modalidades emprendidas por la colonialidad - desde las Misiones Jesuíticas al modelo de agro-negocio exportador en franca expansión en la actualidad.

\section{CONSECUENCIAS, IMPACTOS TERRITORIALES Y VIOLENCIA PERMANENTE EN LAS FRONTERAS}

A lo largo del estudio, fue posible comprender que la colonización de la región de la cuenca del Plata siempre ha pasado por conflictos, primero entre las coronas ibéricas, entre éstas y los jesuitas, entre los Estados nacionales independientes y entre los propios agentes económicos que sucesivamente explotaron el espacio. Desde el ciclo de la yerba mate, pasando por las madereras, y actualmente con la priorización del mercado agroexportador, las fronteras del cono-Sur siempre fueron vistas mucho más como un problema a resolver que un espacio a ser comprendido e incorporado en sus particularidades. 
Este contexto, caracterizado por la ocupación violenta y la apropiación territorial orientada a la explotación económica en beneficio solamente de aquellos que ven en la naturaleza el recurso a dominar, se caracteriza por la negación de la existencia y de la legitimidad de las poblaciones y valores locales, pues sólo subyugando aquel que es originario es que la colonialidad se consolida y alcanza sus finalidades.

La presencia guaraní en la región es conocida desde los primeros contactos con el europeo aún en el siglo XVI y, mientras se mostró útil a los intereses coloniales, fue incentivada y organizada por el sistema reduccional, que, con la conversión y la fijación en el territorio, ampliación de los dominios hispanos en los lejanos bosques de la cuenca del Plata.

De todas las actividades coloniales, los conflictos y treguas entre Portugal y España, el desplazamiento forzado de los territorios más al sur, la obliteración cultural, la usurpación del espacio, pasando por las negociaciones territoriales entre dos coronas ambiciosas - todos estos eventos sólo se dejaron externalidades a los guaraníes, y ningún beneficio.

Desde el momento en que la organización misional dejó de ser conveniente, toda la estructura social y política que componía la realidad del guaraní se desvaneció, sin que ninguna forma de ajuste ocurriera, solamente el abandono y la segregación. Después de tantos acuerdos, tratados y acomodaciones de intereses de una elite colonial inapta y corrupta, tuvo lugar la omisión y la ineficiencia de jóvenes Estados nacionales en conflictos sucesivos, disputando fronteras, matas y ríos en guerras crueles.

Los imperios y repúblicas que siguieron, pasaron a priorizar las formas desarrollistas, volcadas a los mercados e intereses externos, distribuyendo beneplácitos a algunos favorecidos que compusieron las élites locales. La génesis de un pensamiento económicamente liberal, pero políticamente conservador, dio ocasión al patrimonialismo y a la actuación estatal en beneficio de pocos, y, lógicamente, en este contexto no cabe ninguna forma de reconocimiento de derechos a las comunidades tradicionales locales.

El indígena, desde el período colonial considerado inapto, indolente y bárbaro, jamás logró el puesto de protagonista, sino que permaneció en el papel de víctima de explotación del trabajo, expoliación territorial, cuando no del 
exterminio, con la connivencia de un poder que busca silenciar y excluir una presencia humana de tiempos inmemoriales.

Actualmente, aquellos que se beneficiaron de una estrategia neocolonial, de titulación y oficialización de la propiedad de la tierra y apropiación de la naturaleza en beneficio de un mercado externo ávido por recursos naturales a costos económicos bajos y costos socioambientales altos, representan el mayor desafío a la supervivencia de la etnia guaraní. Las prioridades, desde los tiempos coloniales poco han cambiado.

El reconocimiento de que la sociedad envolvente se superpuso forzosamente al territorio legado por la presencia inmemorial guaraní es una idea completamente opuesta a las estrategias de la dominación colonial. Y esta no queda restringida a esa región - en todos los espacios de la colonialidad las sociedades tradicionales sólo mantienen su existencia debido a un enorme esfuerzo de resistencias y embates sociales.

Se produjo que, con la actividad misionera que se desarrolló en este amplio espacio por casi ciento cincuenta años, en diferentes ciclos y sitios - desde el Itatín, al Guairá y el Tape - es innegable que esta presencia se mantuvo con mayor fuerza. A diferencia de otras sociedades que fueron de todo exterminadas o disueltas, las Misiones, en todo su potencial gregario, contribuyeron a la supervivencia de un número expresivo de guaraníes.

El Paraguay es un ejemplo de esta resistencia, que mantiene hasta hoy la fuerte presencia guaraní social y cultural en su población. El dibujo tardío de las fronteras, que fueran oficialmente por doscientos cincuenta años de dominio español, y sólo incorporadas por Portugal después de los tratados sucesivos, también contribuyó a la configuración actual del territorio en el sur de Brasil, ya se efectuara dentro de los parámetros del sistema capitalista consolidado, a diferencia de la tradición portuguesa del monocultivo del azúcar en las zonas costeras que inauguraron la era mercantilista.

Cuando de la titulación de estas tierras, ya a mediados del siglo XX, la organización de este espacio ocurre de forma controlada por el Estado, conciliando sus intereses a los intereses de particulares que se beneficiaron de todas las formas, desde el bajo valor pagado por las tierras, al desbaste de la mata y comercio de madera, incluso por la burocracia local con sus títulos, matrículas y favores políticos. 
Pasada esta cuestión, el agro negocio dominó el espacio de vez, conformando toda la dinámica socioeconómica al modelo monocultor de exportación. No se puede olvidar también de todo el aparato desarrollista que se estableció carreteras, hidroeléctricas y obras estructurantes - que jamás tomaron en cuenta, de manera seria, sus impactos ambientales, económicos y sociales.

Para esta realidad, por muchos alentada, y altamente apoyada por los intereses políticos predominantes, los pueblos tradicionales son vistos con gran desprecio, como verdaderos obstáculos a la economía que tanto muestra resultados expresivos. La demarcación de tierras - aunque no suficiente a la cosmología ya la micromovilidad guaraní, pero dentro de una realidad posible - es fuertemente resistida por los propietarios y líderes locales, pues las tierras altamente productivas, con valores de mercado cada vez más altos, despiertan intereses completamente opuestos al modo de ser tradicional.

Cuando los reclaman tal derecho, los guaraníes sufren una serie de represalias, no cuentan con el apoyo del poder público o de la comunidad circundante, no tienen acceso pleno a las políticas públicas mínimas de atención y acaban por soportar una serie de abusos - de amenazas de muerte y agresiones físicas a la destrucción de sus comunidades. Además, la violencia institucionalizada, que ignora la presencia en el territorio, niega la pertenencia bajo la falacia de que no forman parte de un Estado, sino de otro, la ocultación de los problemas e impedimento al modo de vida ya la micromovilidad también se muestran eficientes herramientas de debilitamiento a las comunidades guaraníes.

La conveniente omisión de la presencia indígena en este territorio, que aparentemente funciona muy bien, que demuestra mayor éxito en el modelo hegemónico impuesto, que atiende únicamente a los intereses del capital y del mercado, oculta un histórico de permanente violencia y segregación, que no acoge y no incorpora el guaraní y su modo de ser, ya que éste es incompatible con todo lo que el agrobusiness y el supuesto progreso predican.

De esta forma, se percibe que el proceso colonial permanece en curso, alcanzando sus finalidades con gran eficiencia, haciendo de la dominación y de la explotación su mayor estrategia. Los beneficios permanecen en las manos de pocos, y jamás se revierten a la comunidad local de forma efectiva - y desde el siglo XVI hasta la actualidad, cambian sólo las herramientas utilizadas para este fin. 


\section{CONSIDERACIONES FINALES}

Las Misiones Jesuíticas representan un escenario colonial atípico y ampliamente discutido, desde su génesis y sus motivaciones - en un carácter utópico real o supuesto - hasta su legado como transformación definitiva del espacio y sus contribuciones a la formación de los actuales contornos de los estados sudamericanos.

Es cierto que la presencia indígena y el dirigismo de los sacerdotes de la Compañía de Jesús representó un formato único de la colonización, lo que contribuyó en gran medida a la contención de los avances portugueses durante más de dos siglos. Sólo con la negociación territorial realizada por el Tratado de Madrid, confirmado por el Tratado de El Pardo, es que Portugal, de hecho, se apropia de las zonas del interior de la parte oriental del río Uruguay, y entrega, por su turno, la Colonia del Sacramento, empujando más abajo la presencia hispánica en el espacio, dominando lo que se convertiría en los estados del sur brasileño.

Sucede que el vacío de esta negociación territorial, coincidiendo tanto con la expulsión de los jesuitas al igual que con la incapacidad de la Corona portuguesa para establecer una ocupación organizada y eficiente, dejó como legado un ambiente de fragilidad a los guaraníes, que han perdido su forma tradicional de vida, sus tierras y su identidad, y buscaran un retorno a los bosques, lo que ya no se mostraba de todo lo posible.

A partir del siglo XIX las márgenes de los ríos de la cuenca del Plata pasaron a ser el escenario de la explotación de la yerba mate y de la madera por las compañías particulares, que utilizaron exhaustivamente la mano de obra del guaraní, sin ninguna preocupación efectiva del poder constituido. Fue sólo en la transición del siglo XX que las tierras de este gran espacio interiorano serán ocupadas, ya partir de entonces, convenientemente fraccionadas y comercializadas por los gobiernos de los Estados conforme intereses y estrategias coloniales cada vez más sofisticadas y excluyentes.

Actualmente, el territorio que fue escenario de las Misiones está ocupado por el monocultivo agroexportador, por la pecuaria intensiva y por ciudades planificadas, habitadas por descendientes de inmigrantes europeos. En este contexto, los mercados de commodities reciben total primacía, en detrimento de todos aquellos que, de alguna forma no encajan en este modelo productivo. 
El pueblo guaraní busca en este espacio una forma de coexistencia, pero esta es cada vez más precarizada, invisible, ausente de políticas públicas de atención, de demarcación, en una permanente lucha por la reanudación de un territorio ancestral. El pequeño productor, no encuentra posibilidades de subsistencia sino aquellas impuestas por el poder hegemónico, que orquestra todo el entorno socioeconómico únicamente a su favor.

Este sitio encuentra fragilidades muy específicas, resultado de sucesivas formas de ocupación y dominación que atendían y atienden solamente intereses externos, desde las disputas coloniales a las actuales balanzas comerciales. Comprender que la violencia es permanente y que las fronteras se han dibujado a costa de muchos conflictos, es un paso importante para encontrar una identidad y desarrollar nuevas formas de existencia y resistencia que permitan la supervivencia de las comunidades tradicionales.

\section{REFERENCIAS}

BELASTEGUI, Horacio. Los colonos de Misiones. Posadas, Argentina: EDUNAM, 2006.

CARBONELL, Rafael. Estrategias de desarrollo rural en los Pueblos Guaraníes (1609-1767). Barcelona: Antoni Bosch Editor, 1992.

CORDEIRO, Tiago. A grande aventura dos jesuítas no Brasil. São Paulo: Planeta, 2016.

CORTESÃO, Jaime Zuzarte. Alexandre de Gusmão e o Tratado de Madrid. Prefácio de Celso Amorim. São Paulo: Imprensa Oficial, 2006a. Tomo 1.

CORTESÃO, Jaime Zuzarte. Alexandre de Gusmão e o Tratado de Madrid. São Paulo: Imprensa Oficial, 2006b. Tomo 2.

EQUIPO MAPA GUARANÍ CONTINENTAL. Caderno do Mapa Guarani Continental. Campo Grande, MS: [s.n.], 2016. Disponible en: https://pt.calameo.com/ read/0051616070b3646393dba. Acceso em: 14 nov. 2019.

KERN, Arno Alvarez. Utopia e missões jesuíticas. Porto Alegre: Ed. UFRGS, 1994.

LINI, Priscila. O direito à terra nas missões jesuíticas dos guaranis: entre o individual e o coletivo. 2015. 192 f. Tese (Doutorado em Direito Econômico e Socioambiental)- Escola de Direito, Pontifícia Universidade Católica do Paraná, Curitiba, 2015. 
LUGON, Clóvis. A República Guarani. Tradução de Alcy Cheuyche. São Paulo: Expressão Popular, 2010.

MELIÁ, Bartomeu. Ñande reko nuestro modo de ser. La Paz, Bolívia: CIPCA, 1988.

PASTELLS, Pablo. Historia de la Compañía de Jesus en la Provincia del Paraguay según los documentos originales del Archivo General de Índias. Madrid: Librería General Victoriano Suárez, 1912. Tomo I.

SALLES, Jefferson; BERGOLD, Raul; VANESKI FILHO, Ener. Vidas amargas: indígenas explorados pelas obrages (1860-1950). In: SOUZA FILHO, Carlos Frederico Marés de (Org.). Os Avá-Guarani no Oeste do Paraná: (re)existência em Tekoha Guasu Guavira. Curitiba: Letra da Lei, 2016.

\section{Sobre los autores:}

Antonio Hilario Aguilera Urquiza: Pos doctor (UNTREF-Argentina). Doctor en Antropología (Salamanca). Profesor asociado de la Universidad Federal de Mato Grosso do Sul (UFMS/FACH); profesor del Posgrado en Derecho y Posgrado en Antropología de la UFMS y profesor colaborador del Posgrado en Educación de la Universidad Católica Dom Bosco (UCDB). E-mail: hilarioaguilera@gmail.com, Orcid: http://orcid.org/0000-0002-3375-8630

Priscila Lini: Pos doctora en Derecho por el Programa de Posgrado de la Pontificia Universidad Católica del Paraná (PUC/PR). Doctora en Derecho Económico y Socioambiental por la misma institución. Profesora del Posgrado en Antropología de la Universidad Federal de Mato Grosso do Sul. E-mail: priscila.lini@ufms.br, Orcid: http://orcid.org/0000-0002-1703-566X

Recibido el 4 de abril de 2019

Aprobado para su publicación el 10 de abril de 2019 